\title{
Real-world utilization of PD-1/PD-L1 inhibitors with palliative radiotherapy in patients with metastatic non-small-cell lung cancer
}

zichao zhou ( $\sim$ zhouzichao23@163.com )

Zhejiang Chinese Medical University https://orcid.org/0000-0002-5891-4978

Kaiyan Chen

Zhejiang Cancer Hospital

$\mathrm{Na} \mathrm{Li}$

Wenzhou Medical University

Mingying Xie

Zhejiang Chinese Medical University

Jiamin Sheng

Wenzhou Medical University

Yun Fan

Zhejiang Cancer Hospital

Zhiyu Huang

Zhejiang Cancer Hospital https://orcid.org/0000-0002-8839-4088

\section{Research Article}

Keywords: Non-small-cell lung cancer (NSCLC), Immunotherapy, Radiotherapy, Combination treatment

Posted Date: February 9th, 2022

DOI: https://doi.org/10.21203/rs.3.rs-1322622/v1

License: (c) (i) This work is licensed under a Creative Commons Attribution 4.0 International License.

Read Full License 


\section{Abstract \\ Background}

Programmed cell death protein 1 (PD-1) blockade combined with radiotherapy may be a promising strategy to improve the prognosis of patients with advanced non-small-cell lung cancer (NSCLC). However, the optimum radiotherapy scheme, timing, and location have not been fully determined.

\section{Methods}

We conducted a retrospective study of 57 patients receiving PD-1/PD-ligand 1 (PD-L1) inhibitors with radiotherapy for metastatic NSCLC in Zhejiang Cancer Hospital between June 2017 and December 2019. Data on overall survival (OS), progression-free survival (PFS), treatment response and adverse events were collected. Comparisons based on type of radiation, timing of radiotherapy and number of irradiated lesions were performed.

\section{Results}

The median OS was 25.9 (95\% Cl: 18.4-33.4) months, and the median PFS was 10.3 (95\% Cl: 8.9-11.8) months. The in-field and out-of-field overall response rates were $45.2 \%$ and $32.1 \%$, respectively. Multisite radiotherapy was associated with longer PFS than single-site radiotherapy (19.50 vs. 9.10 months, $\mathrm{P}=$ 0.017). Furthermore, immunotherapy with concurrent radiotherapy tended to have superior outcomes compared with immunotherapy with sequential radiotherapy (OS: NR vs. 20.87 months, $P=0.079$; PFS: 11.4 vs. 9.0 months, $P=0.153)$, as did immunotherapy with stereotactic radiotherapy compared with traditional radiotherapy (OS: 30.6 vs. 25.9 months, $P=0.840$; PFS: 11.1 vs. 9.9 months, $P=0.803$ ). The incidence of treatment-related adverse events (AEs) was $61.4 \%$, but only $5.3 \%$ of patients experienced grade 3 AEs.

\section{Conclusions}

The combination of immunotherapy and radiotherapy demonstrated favourable survival and good tolerability in Chinese patients with advanced NSCLC.

\section{Introduction}

Immune checkpoint inhibitors targeting programmed cell death-1 (PD-1) and PD-ligand 1 (PD-L1) have emerged as effective anticancer therapies in the treatment of patients with metastatic non-small-cell lung cancer (NSCLC)(1). PD-1/PD-L1 inhibitors (with or without chemotherapy) currently are a cornerstone of first-line treatment for metastatic NSCLC and attack cancer cells by reactivating and inducing proliferation of $T$ cells stimulated by antigens in the tumour microenvironment(2-4). KEYNOTE-024 
demonstrated that the 5-year overall survival (OS) rate of advanced patients (with high PD-L1 expression) treated with immunotherapy was approximately double (31.9\% vs. $16.3 \%)$ that in patients with chemotherapy(5). However, only $17 \%-63 \%$ of NSCLC patients respond to immunotherapy-based approaches, necessitating the investigation of further options for nonresponders $(4,6-8)$.

To improve outcome and local disease control for patients who are treated with immunotherapy, efforts have been aimed at combining immunotherapy with radiotherapy. Patients with oligometastatic NSCLC can achieve prolonged survival following metastasis-directed therapies like radiotherapy(9). Radiation causes excessive release of oxygen free radicals to damage the DNA double helix molecular structure, inhibiting tumour proliferation and inducing apoptosis(10). There is ample mechanistic evidence that radiotherapy can enhance the immune response(11-14). Central to this notion are the in-situ tumour vaccination effect and abscopal effect. Radiotherapy enhances the systemic release of antigens from tumour tissue, which are recognized by antigen-presenting cells (e.g., dendritic cells), which recruit and subsequently present these antigens to T lymphocytes (specifically cytotoxic CD8 T cells). Therefore, radiotherapy reprograms cold tumours into hot and inflamed tumours and improves anti-PD-1/PD-L1 immunotherapy (e.g., increases capillary permeability and promotes the expression of PD-L1 by tumour cells).

Several studies have preliminarily demonstrated that immunotherapy combined with radiotherapy improves patient prognosis compared to immunotherapy alone(13-16). However, data are lacking regarding the ideal type of radiation, timing of radiotherapy intervention and number of irradiated lesions. We conducted a real-world database analysis to evaluate the efficacy, safety and related factors of these combination strategies in the Chinese population.

\section{Materials And Methods}

\subsection{Patients}

Among 728 advanced NSCLC patients treated with PD-1/PD-L1 inhibitors, we retrospectively identified 57 consecutive patients between June 2017 and December 2019 at Zhejiang Cancer Hospital. Patients who had wild-type EGFR and ALK tumours, regardless of what type of PD-1/PD-L1 inhibitor was used, met the inclusion criteria. Patients were eligible for the study if they had at least one unirradiated lesion (to monitor the out-of-field response). Patients were given radiotherapy starting 4 weeks before the first dose of immunotherapy and ending 4 weeks after the last dose of immunotherapy. Consistent with a previous study $(16,17)$, a 4-week cut-off was selected to analyse the synergistic effect of immunotherapy and radiotherapy. We also analysed subgroups based on treatment sequence, radiotherapy technology, and irradiated lesion number. According to the treatment sequence, patients were categorized into a group that received immunotherapy prior to or after radiotherapy (sequential arm) or a group that received immunotherapy concurrently with radiotherapy (concurrent arm). Clinical data were obtained from electronic medical records, and all patients provided written informed consent for the use of their tumour specimens. The study received approval from the institutional ethics boards of Zhejiang Cancer Hospital. 


\subsection{Procedures}

We collected baseline data on age, sex, performance status, smoking status, histological features, previous lines of systemic therapy, PD-L1 expression, immunotherapy regimen, and so on. Efficacy was evaluated by imaging every 6 weeks during treatment. Radiation techniques included conventional radiotherapy modalities (three-dimensional conformal radiation therapy [3D-CRT] and intensitymodulated radiation therapy [IMRT] with accurate radiation beam intensity distribution) and stereotactic radiotherapy (SRT) on whose study mainly focused was respiratory gating technique.

OS was calculated from the beginning of combination treatment (the first dose of immunotherapy or immunotherapy) to the date of death from any cause. PFS was calculated from the beginning of combination treatment to the date of progression or death from any cause. Overall response rate (ORR) and disease control rate (DCR) assessments were based on Response Evaluation Criteria in Solid Tumours (RECIST) version 1.1.

\subsection{Statistical analysis}

All statistical analyses were performed with SPSS (version 26.0) and GraphPad Prism (version 8.0). PFS and OS were estimated by the Kaplan-Meier method, and curves were compared with the log-rank test. Univariate and multivariate Cox analyses were performed to ascertain significant predictors of PFS and OS. All reported two-tailed $\mathrm{P}$ values were analysed, and $\mathrm{P} \leq 0.05$ was considered statistically significant.

\section{Results}

\subsection{Patient characteristics and Treatment}

Among the 57 included patients, $80.7 \%$ (46 patients) were males, $71.9 \%$ (41 patients) were current or former smokers, $63.2 \%$ (36 patients) were younger than 65 years, $93.0 \%$ (53 patients) had ECOG scores of 1 or lower, and $68.4 \%$ (39 patients) had multiple metastases. According to histological examinations, $56.1 \%$ (32 patients) had adenocarcinoma, 38.6\% (22 patients) had squamous cell carcinoma, and 5.3\% (3 patients) had other pathologic types, like adenosquamous carcinoma. Regarding the immunotherapy regimen, 45.6\% (26 patients) were treated with single immune agents, 31.6\% (18 patients) received PD1/PD-L1 inhibitors plus platinum-based chemotherapy, and 22.8\% (13 patients) received PD-1/PD-L1 inhibitors plus nonplatinum regimens. A total of $38.6 \%$ (22 patients) received immunotherapy as first-line therapy, and $61.4 \%$ (35 patients) received immunotherapy as second- or subsequent-line therapy. Regarding the irradiation regimen, 24.6\% (14 patients) received SRT, 75.4\% (43 patients) received traditional radiotherapy, $82.5 \%$ (47 patients) were treated with single-site radiotherapy, and $17.5 \%$ (10 patients) received multisite radiotherapy. In addition, lung $(\mathrm{N}=16,28.1 \%)$, bone $(\mathrm{N}=13,22.8 \%)$, and brain $(\mathrm{N}=22,38.6 \%$ ) lesions were the most often to be irradiated. Regarding the treatment sequence of radiotherapy, 52.6\% (30 patients) received PD-1/PD-L1 inhibitors and radiotherapy concurrently, and the rest received sequential PD-1/PD-L1 inhibitors and radiotherapy. The patient characteristics are summarized in Table 1. 
Page 5/21 
Table 1

Baseline of patient and treatment characteristics.

\begin{tabular}{|c|c|c|}
\hline Characteristic & All Patients $n=57$ & $\%$ \\
\hline \multicolumn{3}{|l|}{ Age (years) } \\
\hline$<65$ & 36 & 63.2 \\
\hline$\geq 65$ & 21 & 36.8 \\
\hline \multicolumn{3}{|l|}{ Gender } \\
\hline Female & 11 & 19.3 \\
\hline Male & 46 & 80.7 \\
\hline \multicolumn{3}{|l|}{ ECOG performance score } \\
\hline $0-1$ & 53 & 93 \\
\hline 2 & 4 & 7 \\
\hline \multicolumn{3}{|l|}{ Histological features } \\
\hline adenocarcinoma & 32 & 56.1 \\
\hline squamous cell carcinoma & 22 & 38.6 \\
\hline Other & 3 & 5.3 \\
\hline \multicolumn{3}{|l|}{ Smoking status } \\
\hline Current/former & 41 & 71.9 \\
\hline Never smoker & 16 & 28.1 \\
\hline \multicolumn{3}{|l|}{ PD-L1 status } \\
\hline$\geq 1 \%$ & 8 & 14 \\
\hline$<1 \%$ & 8 & 14 \\
\hline Unknown & 41 & 72 \\
\hline \multicolumn{3}{|l|}{ Metastasis sites } \\
\hline solitary & 39 & 68.4 \\
\hline multiple & 18 & 31.6 \\
\hline \multicolumn{3}{|c|}{ Prior lines of systemic therapy } \\
\hline 0 & 22 & 38.6 \\
\hline$\geq 1$ & 35 & 61.4 \\
\hline Immunotherapy regimen & & \\
\hline
\end{tabular}




\begin{tabular}{|lll|}
\hline Characteristic & All Patients $\boldsymbol{n}=\mathbf{5 7}$ & $\%$ \\
\hline immune single agent & 26 & 45.6 \\
\hline PD-1/PD-L1 inhibitor plus platinum-based chemotherapy & 18 & 31.6 \\
\hline PD-1/PD-L1 inhibitor plus non-platinum regimens & 13 & 22.8 \\
\hline Type of radiation & 43 & 75.4 \\
\hline Traditional RT a) & 14 & 24.6 \\
\hline SRT b) & & 52.6 \\
\hline Treatment time of RT & 30 & 47.4 \\
\hline concurrent & 27 & 82.5 \\
\hline sequential c) & & 17.5 \\
\hline No. of irradiated lesion & 47 & \\
\hline single-site RT & 10 & 28.1 \\
\hline multiple-site RT & & 22.8 \\
\hline Irradiated lesion & 16 & 38.6 \\
\hline Lung & 13 & \\
\hline Bone & 22 & \\
\hline Brain & 6 & \\
\hline Other & & \\
\hline $\begin{array}{l}\text { a) RT: radiotherapy. } \\
\text { b) SRT: stereotactic radiotherapy. }\end{array}$ & & \\
\hline $\begin{array}{l}\text { c) Include patients who received radiation less than } \\
\text { of immunotherapy. }\end{array}$ & & \\
\hline
\end{tabular}

\subsection{Evaluating patient outcomes}

With a median follow-up time of 20.5 months ( $95 \%$ confidence interval (CI): 17.9-23.1), the median OS was 25.9 (95\% Cl: 18.4-33.4) months for all evaluable patients. We further analysed the relationship between different treatment parameters. Regarding the timing of radiotherapy intervention, 30 patients received a combination of immunotherapy with concurrent radiotherapy, which was associated with a trend towards a longer OS, although the difference was not significant (NR and 20.9 months, $P=0.079$ ). Regarding the number of irradiated lesions, the median OS was 25.87 and NR months $(P=0.293)$ for patients who received single-site and multisite radiotherapy. When stratified by irradiation type, SRT 
demonstrated longer OS than traditional radiotherapy, although no significant difference was reached (30.6 vs. $25.9, P=0.840$ ). Unfortunately, we did not determine independent prognostic factors affecting OS (Table 2). 
Table 2

Univariate and multivariate cox regression analyses estimating the associations of different clinical factors with patients' overall survival.

\begin{tabular}{|c|c|c|c|c|c|c|}
\hline & $\begin{array}{l}\text { Crude } \\
\text { HR }\end{array}$ & $95 \% \mathrm{Cl}$ & $\begin{array}{l}P \\
\text { value }\end{array}$ & $\begin{array}{l}\text { Adjust } \\
\text { HR }\end{array}$ & $95 \% \mathrm{Cl}$ & $\begin{array}{l}P \\
\text { value }\end{array}$ \\
\hline \multicolumn{7}{|l|}{ Age (years) } \\
\hline$<65$ & 1 (ref) & & & 1 (ref) & & \\
\hline$\geq 65$ & 2.1 & $\begin{array}{l}0.9- \\
5.0\end{array}$ & 0.098 & 1.9 & $\begin{array}{l}0.8- \\
4.8\end{array}$ & 0.144 \\
\hline \multicolumn{7}{|l|}{ Gender } \\
\hline Female & 1 (ref) & & & & & \\
\hline Male & 0.6 & $\begin{array}{l}0.2- \\
1.7\end{array}$ & 0.339 & & & \\
\hline \multicolumn{7}{|l|}{ ECOG performance score } \\
\hline $0-1$ & 1 (ref) & & & & & \\
\hline 2 & 2.0 & $\begin{array}{l}0.5- \\
8.7\end{array}$ & 0.356 & & & \\
\hline \multicolumn{7}{|l|}{ Histological features } \\
\hline adenocarcinoma & 1 (ref) & & & & & \\
\hline squamous cell carcinoma & 0.6 & $\begin{array}{l}0.2- \\
1.7\end{array}$ & 0.360 & & & \\
\hline Other & 1.2 & $\begin{array}{l}0.6- \\
2.6\end{array}$ & 0.592 & & & \\
\hline \multicolumn{7}{|l|}{ Smoking status } \\
\hline Current/former & 1 (ref) & & & & & \\
\hline Never smoker & 0.9 & $\begin{array}{l}0.3- \\
2.3\end{array}$ & 0.812 & & & \\
\hline \multicolumn{7}{|l|}{ PD-L1 status } \\
\hline$<1 \%$ & 1 (ref) & & & & & \\
\hline$\geq 1 \%$ & 3.1 & $\begin{array}{l}0.3- \\
29.8\end{array}$ & 0.335 & & & \\
\hline
\end{tabular}
a) RT: radiotherapy.
b) SRT: stereotactic radiotherapy.
c) Include patients who received radiation less than 4 weeks before the first dose or after the last dose of immunotherapy. 


\begin{tabular}{|c|c|c|c|c|c|c|}
\hline & $\begin{array}{l}\text { Crude } \\
\text { HR }\end{array}$ & $95 \% \mathrm{Cl}$ & $\begin{array}{l}P \\
\text { value }\end{array}$ & $\begin{array}{l}\text { Adjust } \\
\mathrm{HR}\end{array}$ & $95 \% \mathrm{Cl}$ & $\begin{array}{l}P \\
\text { value }\end{array}$ \\
\hline \multicolumn{7}{|l|}{ Metastasis sites } \\
\hline multiple & 1 (ref) & & & 1 (ref) & & \\
\hline solitary & 0.3 & $\begin{array}{l}0.1- \\
0.9\end{array}$ & 0.072 & 0.4 & $\begin{array}{l}0.1- \\
1.3\end{array}$ & 0.112 \\
\hline \multicolumn{7}{|l|}{ Prior lines of systemic therapy } \\
\hline 0 & 1 (ref) & & & & & \\
\hline$\geq 1$ & 1.1 & $\begin{array}{l}0.4- \\
2.6\end{array}$ & 0.868 & & & \\
\hline \multicolumn{7}{|l|}{ Immunotherapy regimen } \\
\hline immune single agent & 1 (ref) & & & & & \\
\hline $\begin{array}{l}\text { PD-1/PD-L1 inhibitor plus platinum-based } \\
\text { chemotherapy }\end{array}$ & 1.1 & $\begin{array}{l}0.4- \\
3.0\end{array}$ & 0.910 & & & \\
\hline $\begin{array}{l}\text { PD-1/PD-L1 inhibitor plus non-platinum } \\
\text { regimens }\end{array}$ & 0.9 & $\begin{array}{l}0.5- \\
1.6\end{array}$ & 0.755 & & & \\
\hline \multicolumn{7}{|l|}{ Irradiated schema } \\
\hline Traditional RT a) & 1 (ref) & & & & & \\
\hline SRT b) & 0.9 & $\begin{array}{l}0.3- \\
2.5\end{array}$ & 0.840 & & & \\
\hline \multicolumn{7}{|l|}{ Treatment time of RT } \\
\hline sequential ${ }^{c}$ ) & 1 (ref) & & & 1 (ref) & & \\
\hline concurrent & 0.5 & $\begin{array}{l}0.2- \\
1.1\end{array}$ & 0.079 & 0.9 & $\begin{array}{l}0.3- \\
2.6\end{array}$ & 0.885 \\
\hline \multicolumn{7}{|l|}{ No. of irradiated lesion } \\
\hline single-site RT & 1 (ref) & & & & & \\
\hline multiple-site RT & 0.5 & $\begin{array}{l}0.2- \\
1.5\end{array}$ & 0.293 & & & \\
\hline
\end{tabular}
a) RT: radiotherapy.
b) SRT: stereotactic radiotherapy.
c) Include patients who received radiation less than 4 weeks before the first dose or after the last dose of immunotherapy. 




Kaplan-Meier analysis showed that the median PFS was 10.3 (95\% Cl: 8.9-11.8) months in the entire population. Regarding the treatment sequence of radiotherapy, the group that received immunotherapy administered concurrently with radiotherapy showed a tendency to have longer PFS, but the difference was not statistically significant (11.4 vs. 9.0 months, $P=0.153$ ). Regarding the number of irradiated lesions, the multisite group showed significantly superior median PFS (19.50 vs. 9.10 months, $P=0.017$ ). The SRT group demonstrated longer PFS than the traditional radiotherapy group, although no significant difference was reached (11.1 vs. 9.9 months, $P=0.803)$, potentially (Table 3 ). 
Table 3

Univariate and multivariate cox regression analyses estimating the associations of different clinical factors with patients' progress-free survival.

\begin{tabular}{|c|c|c|c|c|c|c|}
\hline & $\begin{array}{l}\text { Crude } \\
\text { HR }\end{array}$ & $95 \% \mathrm{Cl}$ & $\begin{array}{l}P \\
\text { value }\end{array}$ & $\begin{array}{l}\text { Adjust } \\
\mathrm{HR}\end{array}$ & $95 \% \mathrm{Cl}$ & $\begin{array}{l}P \\
\text { value }\end{array}$ \\
\hline \multicolumn{7}{|l|}{ Age (years) } \\
\hline$<65$ & 1 (ref) & & & & & \\
\hline$\geq 65$ & 1.0 & $\begin{array}{l}0.6- \\
1.8\end{array}$ & 0.984 & & & \\
\hline \multicolumn{7}{|l|}{ Gender } \\
\hline Female & 1 (ref) & & & & & \\
\hline Male & 0.7 & $\begin{array}{l}0.3- \\
1.4\end{array}$ & 0.312 & & & \\
\hline \multicolumn{7}{|l|}{ ECOG performance score } \\
\hline $0-1$ & 1 (ref) & & & & & \\
\hline 2 & 1.1 & $\begin{array}{l}0.4- \\
3.2\end{array}$ & 0.827 & & & \\
\hline \multicolumn{7}{|l|}{ Histological features } \\
\hline adenocarcinoma & 1 (ref) & & & & & \\
\hline squamous cell carcinoma & 0.9 & $\begin{array}{l}0.5- \\
1.5\end{array}$ & 0.590 & & & \\
\hline Other & 1.0 & $\begin{array}{l}0.6- \\
1.9\end{array}$ & 0.898 & & & \\
\hline \multicolumn{7}{|l|}{ Smoking status } \\
\hline Current/former & 1 (ref) & & & & & \\
\hline Never smoker & 0.8 & $\begin{array}{l}0.4- \\
1.4\end{array}$ & 0.395 & & & \\
\hline \multicolumn{7}{|l|}{ PD-L1 status } \\
\hline$<1 \%$ & 1 (ref) & & & & & \\
\hline$\geq 1 \%$ & 1.2 & $\begin{array}{l}0.4- \\
3.7\end{array}$ & 0.710 & & & \\
\hline
\end{tabular}
a) RT: radiotherapy.
b) SRT: stereotactic radiotherapy.
c) Include patients who received radiation less than 4 weeks before the first dose or after the last dose of immunotherapy. 


\begin{tabular}{|c|c|c|c|c|c|c|}
\hline & $\begin{array}{l}\text { Crude } \\
\text { HR }\end{array}$ & $95 \% \mathrm{Cl}$ & $\begin{array}{l}P \\
\text { value }\end{array}$ & $\begin{array}{l}\text { Adjust } \\
\text { HR }\end{array}$ & $95 \% \mathrm{Cl}$ & $\begin{array}{l}P \\
\text { value }\end{array}$ \\
\hline \multicolumn{7}{|l|}{ Metastasis sites } \\
\hline multiple & 1 (ref) & & & & & \\
\hline solitary & 0.7 & $\begin{array}{l}0.4- \\
1.2\end{array}$ & 0.238 & & & \\
\hline \multicolumn{7}{|l|}{ No. of prior therapies } \\
\hline 1 & 1 (ref) & & & & & \\
\hline$\geq 2$ & 1.1 & $\begin{array}{l}0.6- \\
1.9\end{array}$ & 0.846 & & & \\
\hline \multicolumn{7}{|l|}{ Immunotherapy regimen } \\
\hline immune single agent & 1 (ref) & & & 1 (ref) & & \\
\hline $\begin{array}{l}\text { PD-1/PD-L1 inhibitor plus platinum-based } \\
\text { chemotherapy }\end{array}$ & 1.7 & $\begin{array}{l}0.8- \\
3.4\end{array}$ & 0.147 & & & \\
\hline $\begin{array}{l}\text { PD-1/PD-L1 inhibitor plus non-platinum } \\
\text { regimens }\end{array}$ & 1.5 & $\begin{array}{l}1.1- \\
2.2\end{array}$ & 0.024 & 1.5 & $\begin{array}{l}0.7- \\
3.1\end{array}$ & 0.249 \\
\hline \multicolumn{7}{|l|}{ Irradiated schema } \\
\hline Traditional RT a) & 1 (ref) & & & & & \\
\hline $\mathrm{SRT} \mathrm{b}^{\mathrm{n}}$ & 0.9 & $\begin{array}{l}0.5- \\
1.8\end{array}$ & 0.803 & & & \\
\hline \multicolumn{7}{|l|}{ Treatment time of RT } \\
\hline sequential c) & 1 (ref) & & & & & \\
\hline concurrent & 0.7 & $\begin{array}{l}0.4- \\
1.2\end{array}$ & 0.153 & & & \\
\hline \multicolumn{7}{|l|}{ No. of irradiated lesion } \\
\hline single-site RT & 1 (ref) & & & 1 (ref) & & \\
\hline multiple-site RT & 0.5 & $\begin{array}{l}0.3- \\
0.8\end{array}$ & 0.017 & 0.4 & $\begin{array}{l}0.2- \\
1.0\end{array}$ & 0.048 \\
\hline
\end{tabular}
a) RT: radiotherapy.
b) SRT: stereotactic radiotherapy.
c) Include patients who received radiation less than 4 weeks before the first dose or after the last dose of immunotherapy. 


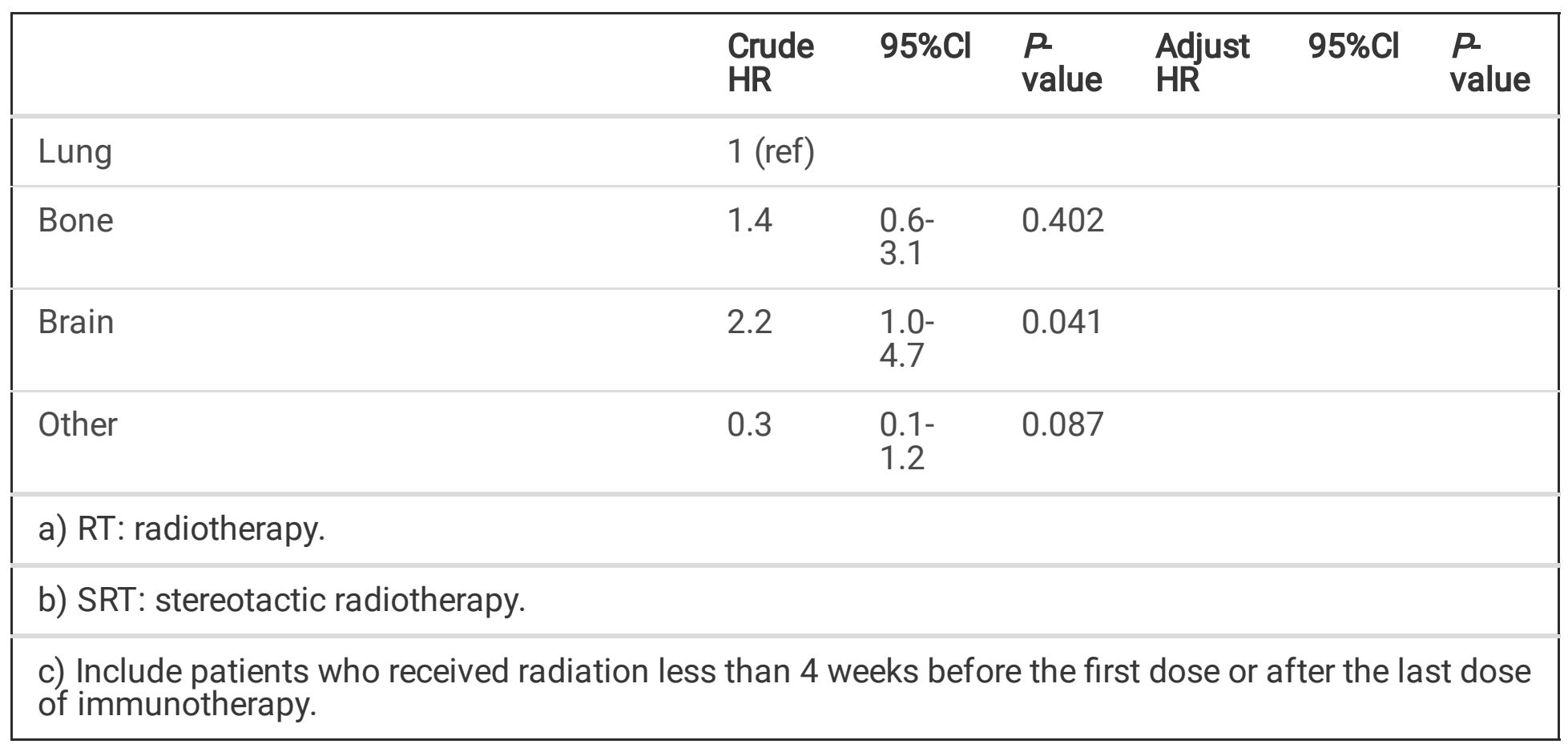

The best in-field and out-of-field ORRs were $45.2 \%$ and $32.1 \%(P=0.208)$, respectively, and the DCRs were $97.6 \%$ and $94.3 \%(P=0.627)$. ORR and DCR (whether local or distant) were not significantly correlated with the type of radiation, timing of radiotherapy or number of irradiated lesions.

\subsection{Treatment toxicity}

The treatment-related AEs are displayed in Table 4. The incidence of treatment-related AEs was $61.4 \%$ $(n=35)$. Pneumonitis $(22.8 \%)$, rash $(17.5 \%)$ and hepatic insufficiency $(15.8 \%)$ occurred most commonly. Only 3 patients $(5.3 \%)$ experienced grade 3 events: pneumonitis $(n=1)$, rash $(n=1)$ and hepatic insufficiency $(n=1)$. 
Table 4

Treatment-related adverse events in 57 patients evaluable for toxicity of combined immunotherapy with radiotherapy therapy.

\begin{tabular}{|llll|}
\hline \multirow{2}{*}{ Treatment-related AEs } & \multicolumn{3}{l|}{ All patient (N = 57) } \\
\cline { 2 - 4 } & Any grade & Grade 1-2 & Grade 3 \\
\hline All AEs & $35(61.4 \%)$ & $32(56.1 \%)$ & $3(5.3 \%)$ \\
\hline Pneumonitis & $13(22.8 \%)$ & $12(21.1 \%)$ & $1(1.7 \%)$ \\
\hline Rash & $10(17.5 \%)$ & $9(15.8 \%)$ & $1(1.7 \%)$ \\
\hline Hepatic Insufficiency & $9(15.8 \%)$ & $8(14.0 \%)$ & $1(1.8 \%)$ \\
\hline Endocrinopathies & $3(5.3 \%)$ & $3(5.3 \%)$ & $0(0 \%)$ \\
\hline Thyroid dysfunction & $3(5.3 \%)$ & $3(5.3 \%)$ & $0(0 \%)$ \\
\hline renal insufficiency & $2(3.5 \%)$ & $2(3.5 \%)$ & $0(0 \%)$ \\
\hline Other & $3(5.3 \%)$ & $3(5.3 \%)$ & $0(0 \%)$ \\
\hline
\end{tabular}

We also evaluated the associations between $\mathrm{AE}$ incidence and radiotherapy parameters. The rates of treatment-related AEs were similar between the concurrent and sequential radiotherapy groups, the multisite and single-site radiation groups, and the groups with different radiation types $(P>0.05)$. Pneumonitis is a major concern in lung cancer, and the incidence of pneumonitis was similar for patients receiving immunotherapy with thoracic radiotherapy and patients treated without thoracic radiotherapy (31.6\% vs. $18.4 \%, P=0.435)$.

\section{Discussion}

In the present study, we described the efficacy and safety of immunotherapy combined with radiotherapy in 57 NSCLC patients. Among the evaluable patients, the median OS was 25.9 months, and the median PFS was 10.3 months. The in-field and out-of-field overall response rates were $45.2 \%$ and $32.1 \%$, respectively; the disease control rates were $97.6 \%$ and $94.3 \%$. Furthermore, the combination of immunotherapy with radiotherapy was well tolerated and was not associated with an increase in the rate of pneumonitis.

Immunotherapy combined with radiotherapy showed longer OS and PFS in our study than in previous studies in which patients received immunotherapy alone, with an OS of 11.8-22.0 months and a PFS of 4.0-9.0 months $(18,19)$, indicating that combination therapy could be a good strategy in metastatic NSCLC patients. There is growing evidence to suggest that a focus on combining immunotherapy with radiotherapy is warranted. A secondary analysis of the phase I KEYNOTE-001 study assessed 98 patients and suggested that patients who received pembrolizumab and had previously received radiotherapy history had longer PFS (4.4 months vs. 2.1 months, $P=0.019)$ and OS (10.7 months vs. 5.3 months, $P=$ 
0.026) than those who did not receive radiotherapy(20). In the PEMBRO-RT (phase 2, n=76) and MDACC (phase $1 / 2, n=72$ ) trials, patients with metastatic NSCLC were divided into a pembrolizumab with radiotherapy group and a pembrolizumab alone group $(14,21)$. Although there were no significant differences in response rates and outcomes when the above two studies were analysed individually, a pooled analysis combining the data from these two randomized trials reported that immunotherapy combined with radiotherapy significantly increased the abscopal response rate and control rate $(41.7 \%$ vs. $19.7 \%, P=0.004 ; 65.3 \%$ vs. $43.4 \%, P=0.007$, respectively), with higher $P F S$ ( 9.0 vs. 4.4 months, $P=$ 0.045 ) and OS (19.2 vs. 8.7 months, $P<0.001)$ (15). Moreover, a systematic review including 18 articles (6 prospective studies) described 1736 patients treated with an ICI-SABR combination; the OS and PFS were 12.4 and 4.6 months, respectively, and abscopal response rates was $41 \%(22)$. Collectively, in line with the findings of our study, the addition of radiotherapy to immunotherapy showed great promise for advanced NSCLC.

To further study the ideal radiotherapy timing, number of lesions to be irradiated, and schedule of combined treatment, subgroup analyses were performed. Patients receiving immunotherapy with concurrent radiotherapy showed a trend to have improved PFS and OS compared to those who were given sequential radiotherapy, although the difference did not reach statistical significance. Although several studies attribute outcome benefits to the abscopal effect $(23,24)$, the exact mechanisms of the concurrent combination are not known and need to be confirmed by future studies with larger sample sizes. In the subgroup analysis of the number of irradiated lesions, multisite radiotherapy was associated with longer PFS than single-site radiotherapy, which was an independent prognostic factor for PFS. However, similar to previous studies(21), the median OS was significantly different. This result may suggest that multisite radiotherapy could prolong systemic lesion control and lead to better prognosis by activating systemic immunity; however, there are many factors affecting $\mathrm{OS}$, such as posterior treatment mode.

A previous study of radiotherapy schemes demonstrated that hypofractionated radiation therapy (HFRT) has a therapeutic advantage compared with conventional fractionated radiation therapy(25). A preclinical study proved that HFRT treatment of the primary tumour could reduce the recruitment of myeloid-derived suppressor cells into tumours and decrease the expression of PD-L1 on those cells, which unleashed the cytotoxicity of CD8+ T cells(26). Although low-dose radiation therapy (LDRT) has an inferior tumourkilling effect, LDRT is conducive to T cell recruitment and reprograms macrophages in the tumour microenvironment(27). Thus, studies to determine which radiotherapy mode can achieve the best combination effect are warranted. In the pooled analysis of the PEMBRO-RT and MDACC trials, the PFS in the SBRT group was significantly longer than that in the traditional radiotherapy group ( $21.1 \mathrm{vs.} 6.8$ months, $P=0.03)(14)$. In a retrospective analysis, patients receiving immunotherapy with SRT $(n=228)$ showed a superior OS compared with those receiving a traditional radiation scheme $(n=2235)(P<0.001)$ (28). However, our study found a similar PFS and OS in the SRT and conventional radiotherapy groups. Several factors might be related to the results. First, the relatively small sample size was a limitation for the detection of potentially significant differences. Second, the lack of PD-L1 assay standardization and 
limited stratification due to the difficulty in obtaining samples from retrospective studies might have affected the results.

There is growing evidence of the encouraging safety profile of immunotherapy combined with radiotherapy. Our study showed no increase in toxicity and a rate of treatment-related AEs of $61.4 \%$, consistent with the range of $50-70 \%$ previously reported $(29,30)$. The incidence of grade 3 AEs was $5.3 \%$. Therefore, administration of immunotherapy combined with radiotherapy does not increase the incidence of AEs in the real world. Pneumonitis is a major concern in lung cancer, and the incidence of pneumonitis was not increased for patients receiving immunotherapy with thoracic radiotherapy. Additionally, patients receiving immunotherapy with concurrent radiotherapy or multisite radiotherapy did not have an increased risk of severe or unexpected toxicities.

This study is limited by its small sample size and retrospective nature. Furthermore, the relationship between PD-L1 expression and outcomes in our combined cohort could not be determined due to the lack of sufficient tissue samples. Additionally, many questions remain about the effect of different radiotherapy doses and fractionation schedules on the magnitude of the immune-boosting effect. Further large-volume, randomized trials are needed to address these unresolved questions.

\section{Conclusion}

Immunotherapy combined with radiotherapy demonstrated favourable survival without increased toxicity in the treatment of patients with advanced NSCLC. Notably, multisite radiotherapy was associated with longer PFS. Patients receiving immunotherapy with concurrent radiotherapy and immunotherapy with SRT showed a tendency to have improved prognosis. The radiotherapy dose and scheme, as well as the timing of radiotherapy intervention, remain to be further studied.

\section{Declarations}

\section{Ethics approval and consent to participate}

Clinical data were obtained from electronic medical records, and all patients provided written informed consent for the use of their tumour specimens. The study received approval from the institutional ethics boards of Zhejiang Cancer Hospital.

\section{Consent for publication}

Not applicable.

\section{Availability of data and materials}

The datasets generated and/or analysed during the current study are not publicly available due to privacy or ethical restrictions but are available from the corresponding author on reasonable request. 


\section{Competing interests}

The authors declare that they have no competing interests.

\section{Funding}

Not applicable.

\section{Authors' contributions}

Z.Z conducted the analysis and interpretation of data, performed the literature search and wrote the manuscript. K.C revised the entire manuscript and guaranteed its integrity. Z.H and YF provided the conception and conceived the framework of the manuscript. NL, M.X and J.S made contributions to acquisition of data. Each author should have participated sufficiently in the work to take public responsibility for appropriate portions of the content.

\section{Acknowledgements}

Not applicable.

\section{References}

1. Proto C, Ferrara R, Signorelli D, et al. Choosing wisely first line immunotherapy in non-small cell lung cancer (NSCLC): what to add and what to leave out. Cancer Treat Rev. 2019;75:39-51.

2. Gandhi L, Rodriguez-Abreu D, Gadgeel S, et al. Pembrolizumab plus Chemotherapy in Metastatic Non-Small-Cell Lung Cancer. N Engl J Med. 2018;378(22):2078-92.

3. West $\mathrm{H}, \mathrm{McCleod} \mathrm{M}$, Hussein $\mathrm{M}$, et al. Atezolizumab in combination with carboplatin plus nabpaclitaxel chemotherapy compared with chemotherapy alone as first-line treatment for metastatic non-squamous non-small-cell lung cancer (IMpower130): a multicentre, randomised, open-label, phase 3 trial. Lancet Oncol. 2019;20(7):924-37.

4. Paz-Ares L, Vicente D, Tafreshi A, et al. A Randomized, Placebo-Controlled Trial of Pembrolizumab Plus Chemotherapy in Patients With Metastatic Squamous NSCLC: Protocol-Specified Final Analysis of KEYNOTE-407. J Thorac Oncol. 2020;15(10):1657-69.

5. Reck M, Rodriguez-Abreu D, Robinson AG, et al. Five-Year Outcomes With Pembrolizumab Versus Chemotherapy for Metastatic Non-Small-Cell Lung Cancer With PD-L1 Tumor Proportion Score $>/=$ 50. J Clin Oncol. 2021;39(21):2339-49.

6. Topalian SL, Hodi FS, Brahmer JR, et al. Safety, activity, and immune correlates of anti-PD-1 antibody in cancer. N Engl J Med. 2012;366(26):2443-54.

7. Langer CJ, Gadgeel SM, Borghaei $\mathrm{H}$, et al. Carboplatin and pemetrexed with or without pembrolizumab for advanced, non-squamous non-small-cell lung cancer: a randomised, phase 2 cohort of the open-label KEYNOTE-021 study. Lancet Oncol. 2016;17(11):1497-508. 
8. Paz-Ares L, Luft A, Vicente D, et al. Pembrolizumab plus Chemotherapy for Squamous Non-Small-Cell Lung Cancer. N Engl J Med. 2018;379(21):2040-51.

9. Pitroda SP, Chmura SJ, Weichselbaum RR. Integration of radiotherapy and immunotherapy for treatment of oligometastases. Lancet Oncol. 2019;20(8):e434-e42.

10. Wright EA, Howard-Flanders P. The influence of oxygen on the radiosensitivity of mammalian tissues. Acta radiol. 1957;48(1):26-32.

11. Huang AC, Postow MA, Orlowski RJ, et al. T-cell invigoration to tumour burden ratio associated with anti-PD-1 response. Nature. 2017;545(7652):60-5.

12. Tian $\mathrm{L}$, Goldstein $\mathrm{A}$, Wang $\mathrm{H}$, et al. Mutual regulation of tumour vessel normalization and immunostimulatory reprogramming. Nature. 2017;544(7649):250-4.

13. Theelen $W$, Chen $D$, Verma V, et al. Pembrolizumab with or without radiotherapy for metastatic nonsmall-cell lung cancer: a pooled analysis of two randomised trials. The Lancet Respiratory medicine; 2020.

14. Welsh J, Menon H, Chen D, et al. Pembrolizumab with or without radiation therapy for metastatic non-small cell lung cancer: a randomized phase I/II trial. J Immunother Cancer. 2020;8(2).

15. Hwang WL, Niemierko A, Hwang KL, et al. Clinical Outcomes in Patients With Metastatic Lung Cancer Treated With PD-1/PD-L1 Inhibitors and Thoracic Radiotherapy. JAMA Oncol. 2018;4(2):253-5.

16. Mohamad O, Diaz de Leon A, Schroeder S, et al. Safety and efficacy of concurrent immune checkpoint inhibitors and hypofractionated body radiotherapy. Oncoimmunology. 2018;7(7):e1440168.

17. Hubbeling HG, Schapira EF, Horick NK, et al. Safety of Combined PD-1 Pathway Inhibition and Intracranial Radiation Therapy in Non-Small Cell Lung Cancer. J Thorac Oncol. 2018;13(4):550-8.

18. Gadgeel S, Rodriguez-Abreu D, Speranza G, et al. Updated Analysis From KEYNOTE-189: Pembrolizumab or Placebo Plus Pemetrexed and Platinum for Previously Untreated Metastatic Nonsquamous Non-Small-Cell Lung Cancer. J Clin Oncol. 2020;38(14):1505-17.

19. Herbst RS, Garon EB, Kim DW, et al. Five Year Survival Update From KEYNOTE-010: Pembrolizumab Versus Docetaxel for Previously Treated, Programmed Death-Ligand 1-Positive Advanced NSCLC. J Thorac Oncol. 2021.

20. Shaverdian N, Lisberg AE, Bornazyan K, et al. Previous radiotherapy and the clinical activity and toxicity of pembrolizumab in the treatment of non-small-cell lung cancer: a secondary analysis of the KEYNOTE-001 phase 1 trial. Lancet Oncol. 2017;18(7):895-903.

21. Theelen W, Peulen HMU, Lalezari F, et al. Effect of Pembrolizumab After Stereotactic Body Radiotherapy vs Pembrolizumab Alone on Tumor Response in Patients With Advanced Non-Small Cell Lung Cancer: Results of the PEMBRO-RT Phase 2 Randomized Clinical Trial. JAMA Oncol. 2019.

22. Chicas-Sett R, Morales-Orue I, Castilla-Martinez J, et al. Stereotactic Ablative Radiotherapy Combined with Immune Checkpoint Inhibitors Reboots the Immune Response Assisted by Immunotherapy in Metastatic Lung Cancer: A Systematic Review. Int J Mol Sci. 2019;20(9). 
23. Ngwa W, Irabor OC, Schoenfeld JD, et al. Using immunotherapy to boost the abscopal effect. Nat Rev Cancer. 2018;18(5):313-22.

24. Tang J, Yu JX, Hubbard-Lucey VM, et al. Trial watch: The clinical trial landscape for PD1/PDL1 immune checkpoint inhibitors. Nat Rev Drug Discov. 2018;17(12):854-5.

25. Chen Y, Gao M, Huang Z, et al. SBRT combined with PD-1/PD-L1 inhibitors in NSCLC treatment: a focus on the mechanisms, advances, and future challenges. J Hematol Oncol. 2020;13(1):105.

26. Lan J, Li R, Yin LM, et al. Targeting Myeloid-derived Suppressor Cells and Programmed Death Ligand 1 Confers Therapeutic Advantage of Ablative Hypofractionated Radiation Therapy Compared With Conventional Fractionated Radiation Therapy. Int J Radiat Oncol Biol Phys. 2018;101(1):74-87.

27. Yin L, Xue J, Li R, et al. Effect of Low-Dose Radiation Therapy on Abscopal Responses to Hypofractionated Radiation Therapy and Anti-PD1 in Mice and Patients With Non-Small Cell Lung Cancer. Int J Radiat Oncol Biol Phys. 2020;108(1):212-24.

28. Foster CC, Sher DJ, Rusthoven CG, et al. Overall survival according to immunotherapy and radiation treatment for metastatic non-small-cell lung cancer: a National Cancer Database analysis. Radiat Oncol. 2019;14(1):18.

29. Lesueur P, Escande A, Thariat J, et al. Safety of combined PD-1 pathway inhibition and radiation therapy for non-small-cell lung cancer: A multicentric retrospective study from the GFPC. Cancer Med. 2018;7(11):5505-13.

30. Satouchi M, Nosaki K, Takahashi T, et al. First-line pembrolizumab vs chemotherapy in metastatic non-small-cell lung cancer: KEYNOTE-024 Japan subset. Cancer Sci. 2020;111(12):4480-9.

\section{Figures}


Figure 1 
Kaplan-Meier curves of overall survival (OS) and progression-free survival (PFS) in 57 advanced nonsmall-cell lung cancer (NSCLC) patients receiving immunotherapy with radiotherapy. (A) NSCLC patients treated with immunotherapy combined with radiotherapy showed a median OS of 25.9 months. (B) The median PFS in the entire population was 10.3 months.

A

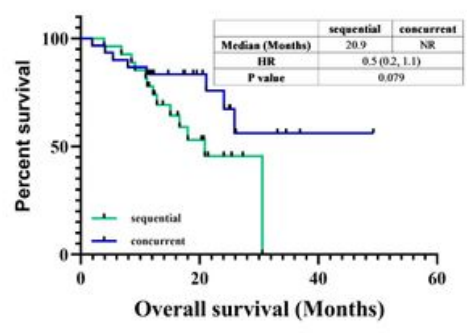

B

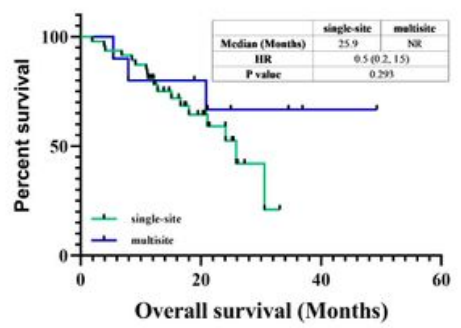

C

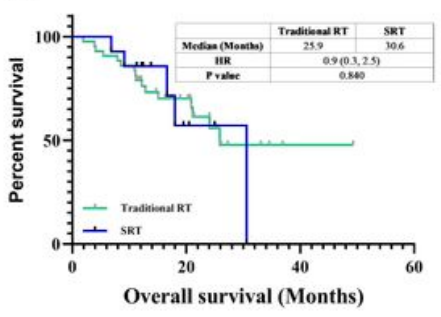

Figure 2

Kaplan-Meier curves of overall survival (OS) in 57 advanced non-small-cell lung cancer (NSCLC) patients receiving immunotherapy with radiotherapy stratified by radiotherapy schedule. (A) Patients receiving immune checkpoint inhibitors concurrently with radiotherapy had improved OS compared with individuals receiving sequential treatment (median OS: not reached versus 20.9 months, $P=0.079$ ). (B, C) The number of irradiated lesions and radiotherapy scheme (single-site versus multisite; traditional radiotherapy versus stereotactic radiotherapy) were not remarkably correlated with OS (both $\boldsymbol{P}>0.05$ ).

A

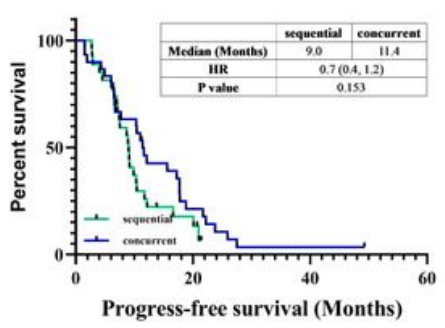

B

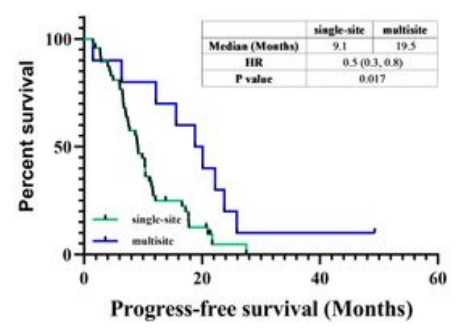

C

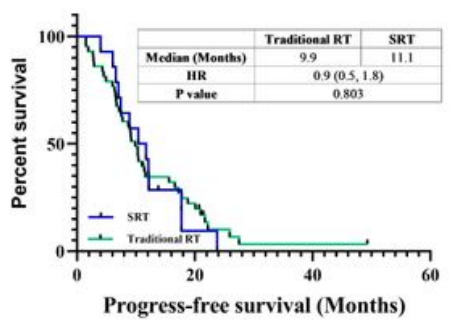

Figure 3

Kaplan-Meier curves of progression-free survival (PFS) in 57 advanced non-small-cell lung cancer (NSCLC) patients receiving immunotherapy with radiotherapy stratified by radiotherapy schedule. $(A, C)$ Timing of radiotherapy and radiation type were not significantly correlated with PFS in advanced NSCLC (both $\mathrm{P}>0.05$ ). (B) Patients who received multisite radiation had significantly longer PFS than those who received single-site radiation (median PFS: 19.50 versus 9.10 months, $\boldsymbol{P}=0.017$ ). 